\title{
Service Quality Attributes Affecting Customer Satisfaction for Bus Transit
}

\author{
Laura Eboli and Gabriella Mazzulla, University of Calabria
}

\begin{abstract}
In this article a tool for measuring customer satisfaction in public transport is proposed. Specifically, a structural equation model is formulated to explore the impact of the relationship between global customer satisfaction and service quality attributes. The public transport service analyzed is the bus service habitually used by University of Calabria students to reach the campus from the urban area of Cosenza (southern Italy). To calibrate the model, some data collected in a survey addressed to a sample of students were used. The proposed model can be useful both to transport agencies and planners to analyze the correlation between service quality attributes and identify the more convenient attributes for improving the supplied service.
\end{abstract}

\section{Introduction}

Over the last few years, companies have gradually focused on service quality and customer satisfaction. This strategy is very profitable for both companies and customers, particularly for transit agencies and passengers. An improvement of the supplied service quality can attract further users. This fact could resolve many problems (e.g., helping to reduce traffic congestion, air and noise pollution, and energy consumption) because individual transport would be used less. For this reason, the development of techniques for customer satisfaction analysis is nec- 
essary. These techniques allow the critical aspects of the supplied services to be identified and customer satisfaction to be increased (Cuomo 2000).

This research explores the relationship between global customer satisfaction (i.e., passenger satisfaction about overall service) and service quality attributes, based on needs and expectations expressed by the customers of public transport services. A structural equation-the structural equation modelling (SEM)-model is proposed. SEM is useful to researchers as a multivariate technique combining regression, factor analysis, and analysis of variance to estimate interrelated dependence relationships simultaneously.

SEM was adopted in several fields of research and generalized by Joreskog (1973) and Wiley (1973). Some applications were proposed, for example, in the fields of psychology and social science (MacCallum and Austin 2000; Muthén et al. 2006), natural science (Mitchell 1992; Grace and Pugesek 1997), and especially in economics and statistics (MacLean and Gray 1998; Eskildsen and Dahlgaard 2000; Boari 2000; Manaresi et al. 2000). Some authors proposed SEM applications in public transport (see, for example, Bamberg and Schmidt 1998; Fillone et al. 2005; Tam et al. 2005). Specifically, SEM was adopted for describing customer satisfaction in public transport services (as an example, see Andreassen 1995; Karlaftis et al. 2001).

The model proposed in this article investigates the impact of bus transit aspects on global customer satisfaction. The service analyzed is habitually used by University of Calabria students to reach the campus from the urban area of Cosenza (southern Italy). To calibrate the model, data collected in a survey addressed to a sample of students were used.

This article begins with an introduction to a theoretical framework of structural equation models. Next, the experimental survey is described and the statistical descriptive analysis of the sample is reported. The last section describes the general structure of the proposed model and presents the model results.

\section{Structural Equation Models}

SEM methodology spread fast as a consequence of the development of specific packages, like LISREL (Joreskog and Sorbom 1988, 1989, 1995) and AMOS (Arbuckle and Wothke 1995). The availability of these packages has encouraged several applications in different contexts. 
This approach allows the modelling of a phenomenon by considering both the unobserved "latent" constructs and the observed indicators that describe the phenomenon.

SEMs are made up of two components: the first describes the relationship between endogenous and exogenous latent variables, and permits the evaluation of both direction and strength of the causal effects among these variables (latent variable model); the second component describes the relationship between latent and observed variables (measurement model).

The basic equation of the latent variable model is the following (Bollen 1989):

$$
\eta=\mathrm{B} \eta+\Gamma \xi+\zeta
$$

where:

$$
\begin{aligned}
& \eta \text { (eta) is an }(m \times 1) \text { vector of the endogenous latent variables } \\
& \xi(\mathrm{xi}) \quad \text { is an }(n \times 1) \text { vector of the exogenous latent variables } \\
& \zeta \text { (zeta) is an }(m \times 1) \text { vector of random variables } \\
& \text { elements of the } \\
& \mathrm{B} \text { (beta) and } \\
& \Gamma \text { (gamma) matrices are the structural coefficients of the model } \\
& \text { B matrix is an }(m \times m) \text { coefficient matrix for the latent } \\
& \text { endogenous variables } \\
& \Gamma \text { matrix is an }(m \times n) \text { coefficient matrix for the latent } \\
& \text { exogenous variables }
\end{aligned}
$$

The basic equations of the measurement model are the following:

$$
x=\Lambda_{x} \xi+\delta
$$

for the exogenous variables

$$
y=\Lambda_{y} \eta+\varepsilon
$$

for the endogenous variables 
where:

$\mathrm{x}$ and $\delta$ (delta) are column $q$-vectors related to the observed exogenous variables and errors, respectively

$\Lambda_{x}$ (lambda) is a $(q \times n)$ structural coefficient matrix for the effects of the latent exogenous variables on the observed variables

$y$ and $\varepsilon$ (epsilon) are column $p$-vectors related to the observed endogenous variables and errors, respectively

$\Lambda_{y} \quad$ is a $(p \times m)$ structural coefficient matrix for the effects of the latent endogenous variables on the observed ones

The structural equation system is generally estimated by using the maximum likelihood method $(\mathrm{ML})$. In other cases, the structural equation model parameters can be estimated by using other estimation methods, such as unweighted least squares (ULS), weighted least squares (WLS), generalized least squares (GLS), and so on. These estimation methods are described in Bollen (1989) and Washington et al. (2003).

For a more detailed discussion on structural equation models, see Joreskog (1973), Bollen (1989), Bagozzi (1994), and Golob (2003).

\section{The Sample Survey}

The sample survey was addressed to University of Calabria students who lived in the urban area of Cosenza. The university is the major center of interest in this area. Unlike other Italian universities, which are located inside the urban center, the University of Calabria is like the Anglo-Saxon campus; it is located outside the city in an area in which there are both university facilities and residential services.

More than 30,000 students attend the university, which is staffed by 2,000 people (March 2006).

A single transit agency (Consorzio Autolinee Cosenza S.r.l) manages the urban bus lines. These service lines are dedicated to the students and are not used by other people. The service is available from 7:30 a.m. to 12:30 p.m. Service frequency is 1 run every 60 minutes; in peak hours service frequency is 1 run every 30 minutes.

An extra-urban service permits connection between the campus and the major towns in the Calabria area. In a working day, about 8,800 students travel by urban bus and 1,200 by extra-urban bus. 
The survey, conducted in April 2006, was addressed to students who use the urban transport services. A total of 763 students was interviewed, for a sampling rate of 8.6 percent. Respondents were asked to provide information about their socioeconomic characteristics and bus service quality. Each student was asked to indicate the faculty, condition of student as "in course" or "out course," and condition of student as "inside" or "outside," and place of residence and domicile. In Italy, out-course conditions relate to a university student who has not finished his or her studies in the prescribed time. Outside students are those living in a place more than an hour from campus. Some student socioeconomic characteristics requested were: age, gender, number of family members, income, number of cars, and number of licensed driving members.

To evaluate bus service quality, the respondent was asked about 16 service attributes. On a scale from 1 to 10, users expressed a rate of importance and a rate of satisfaction on each attribute. In addition, a rate on global service, in terms of both expected and perceived quality, was requested.

The analyzed attributes are shown in Table 1.

\section{Table 1. Service Quality Attributes}

\begin{tabular}{ll}
\hline Attribute & Description \\
\hline Bus stop availability & Availability of bus stop near home \\
Route characteristics & $\begin{array}{l}\text { Route characteristics (number of bus stops, distance between } \\
\text { bus stops, etc.) }\end{array}$ \\
Frequency & Service frequency \\
Reliability & Reliability of buses that come on schedule \\
Bus stop furniture & Availability of shelter and benches at bus stops \\
Overcrowding & Bus overcrowding \\
Cleanliness & Cleanliness of interior, seats, and windows \\
Cost & Cost affordability \\
Information & Availability of schedule/maps at bus stops \\
Promotion & Availability of service information by phone, mail, Internet, etc. \\
Safety on board & Vehicle reliability and competence of drivers \\
Personal security & Safety against crimes on buses \\
Personnel & Helpfulness of personnel \\
Complaints & Administrat ion of complaints \\
Environmental protection & Use of ecological vehicles \\
Bus stop maintenance & Physical condition of bus stops \\
\hline
\end{tabular}


A statistical descriptive analysis of the sample was carried out. Eighty percent of the sample was in-course students and 20 percent was out-course students. The sample was spread over 47 percent male and 53 percent female respondents. Of the student sample, 49 percent was between 21 and 24 years old; 41 percent was between 18 and 20 years old; the other students (10\%) were over 24 years old. The sample was divided between inside (20\%), and outside (80\%) students. Outside interviewed students live in the urban area. Twenty-seven percent of the student sample belonged to the Faculty of Engineering, 21 percent to the Faculty of Arts and Philosophy, 19 percent to the Faculty of Economy, and 27 percent was spread among the Faculty of Mathematical, Physical and Natural Science, Pharmacy, and Political Science. Six percent belonged to interfaculties (Figure 1a). Eighty-five percent of the sample has a driver's license, but 90 percent does not have the car in
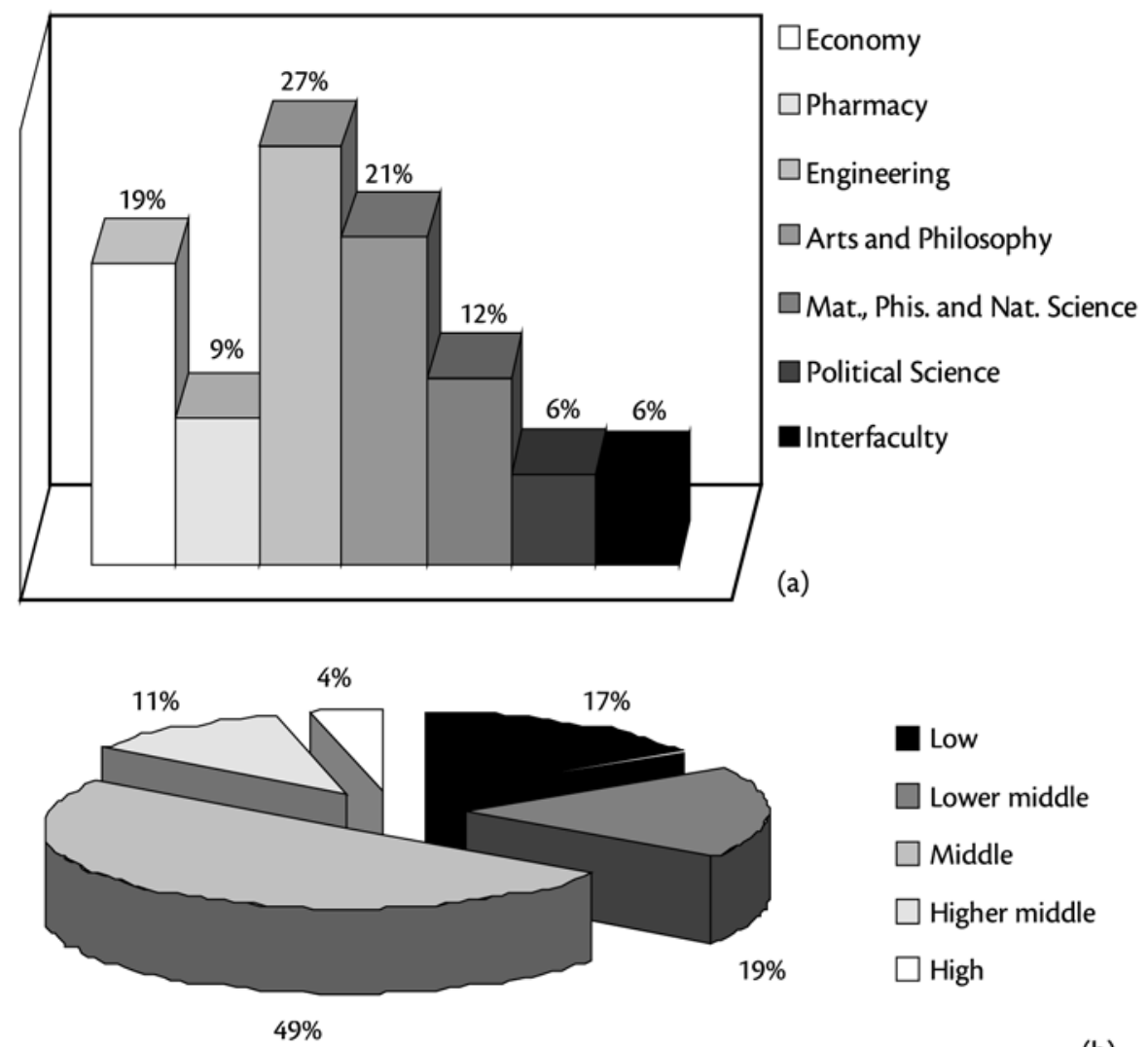

Figure 1. Sample Sharing According to Faculty (a) and Income (b) 
the place of domicile. About 50 percent are from middle-class families and about 35 percent are from the lower-middle class (Figure 1b).

\section{The Proposed Model: General Structure}

In the proposed structural equation model, the observed variables are the 16 service quality attributes evaluated by the user sample and the 2 global service quality indicators (perceived and expected quality). The latent variables are the unobserved service quality aspects that can be explained by the observed variables.

The latent variables were defined by means of an exploratory factor analysis (EFA) implemented in the form of principal component analysis. EFA was conducted by using a correlation matrix. To determine the number of components, only the eigenvalues greater than or equal to 1 were considered (Guttman 1954; Kaiser 1960). An orthogonal rotated solution (Quartimax) was adopted (Carroll 1953). In addition, the KMO test (Kaiser, Mayer and Olkin) and the Barlett sphericity test were effected (Fabbris 1997).

By means of the EFA, four variables were identified. The first variable, service planning and reliability, related to the factors of frequency, reliability, information, promotion, personnel, and complaints. The second variable, comfort and other factors, related to bus stop furniture, overcrowding, cost, environmental protection, and bus stop maintenance. The third variable, safety and cleanliness, related to cleanliness, safety on board, and personal security. The fourth variable, network design, related to bus stop availability and route characteristics.

The latent variable model relates the 4 exogenous latent variables to an endogenous latent variable, named satisfaction; besides, the exogenous variables are correlated among them. The measurement model relates each latent variable to the variable that measures customer satisfaction. Specifically, we supposed that the exogenous latent variables are measured by the 16 service quality attributes and the latent variable "satisfaction" is measured by the indicators of perceptions and expectations.

By effecting some preparatory calibrations, we propose the final model shown in Figure 2. 


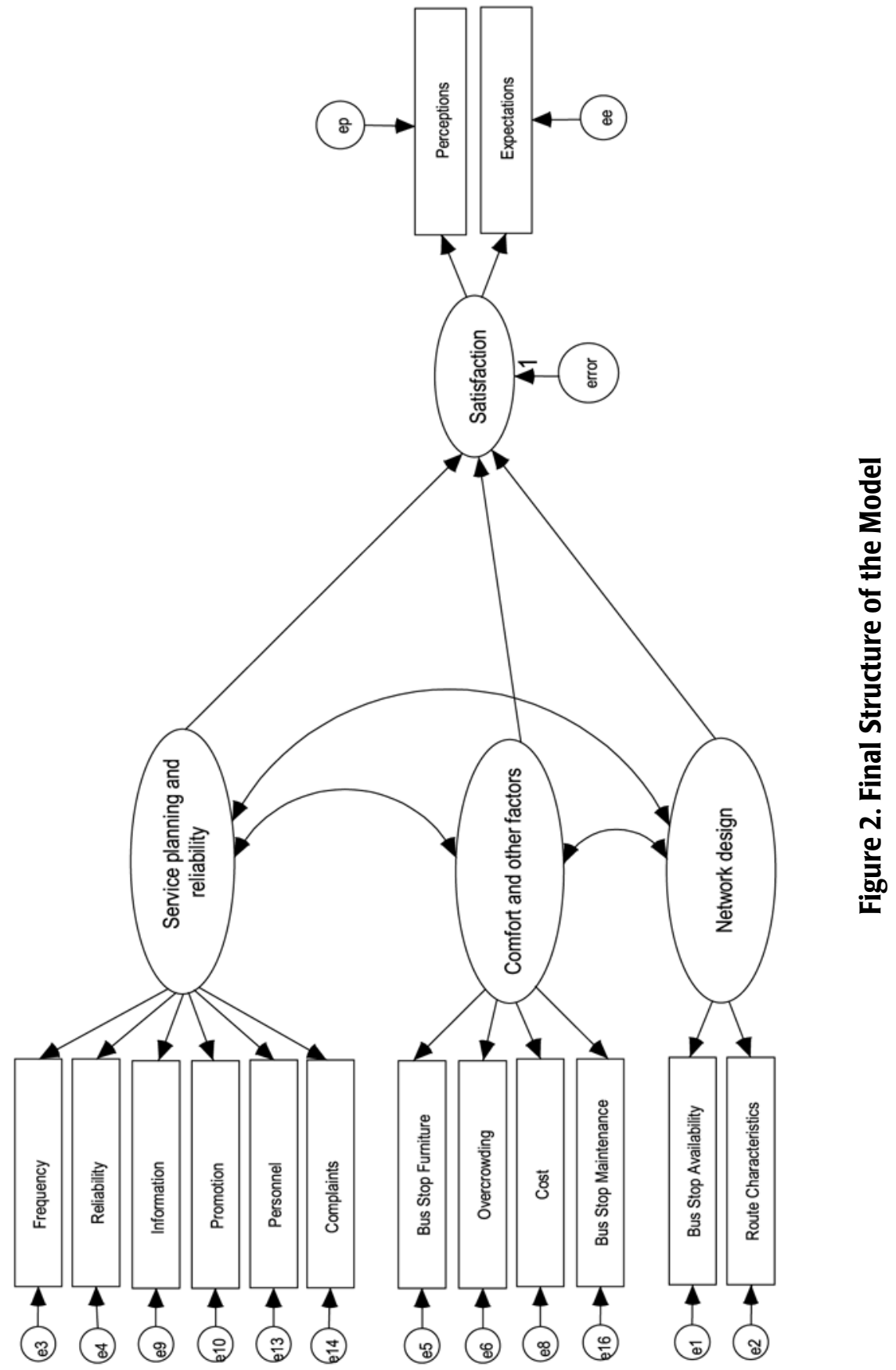




\section{The Proposed Model: Results}

The model was calibrated by using the AMOS 4.0 package from SmallWaters Corporation (Arbuckle and Wothke 1995). Model results are shown in Tables 2 and 3. Specifically, the parameters estimated, the standard error (S.E.), the critical ratio (C.R.), and the level of statistical significance (P) of each variable are reported in Table 2; some tests on the goodness of fit are given in Table 3.

To estimate the model, the constriction of a parameter to a value equal to 1 was necessary. Afterwards, the estimated coefficients were standardized. All parameters have a correct sign and assume a value statistically different from zero, at a good level of significance. Only one parameter is less statistically significant than the others (level of significance of $9.0 \%$ ).

The minimum value of the discrepancy function is 304.705 ; this value is statistically significant according to the chi-squared test.

The tests on the goodness of fit are quite satisfactory. The goodness of fit index (GFI) is at 0.947, the adjusted goodness of fit index (AGFI) is 0.922 , and the comparative fit index (CFI) is 0.877 . These indexes are bounded above by 1 , which indicates a perfect

fit; therefore, the indexes obtained from the model are very good. The root mean square residual (RMR) index has a value of 0.150 , and the root mean square error of approximation (RMSEA) has a value of 0.066; the values of these indexes are low and therefore are quite good. For a more detailed discussion on the indexes, see Arbuckle and Wothke (1995) and Bollen (1989).

The latent variable with a major effect on global customer satisfaction is service planning and reliability, which has a coefficient value of 0.697 (standardized weight). The network design and the comfort and other factors latent variables have considerable impacts, even if lower than the previous (0.237 and 0.199, respectively).

The route characteristics observed variable has a major impact on the network design exogenous latent variable (0.649). Similarly, the complaints factor has a major impact on the service planning and reliability latent variable (0.623), even if all the other factors have a considerable weight. Finally, the bus stop maintenance factor has a major impact on the comfort and other factors latent variable (0.701). 


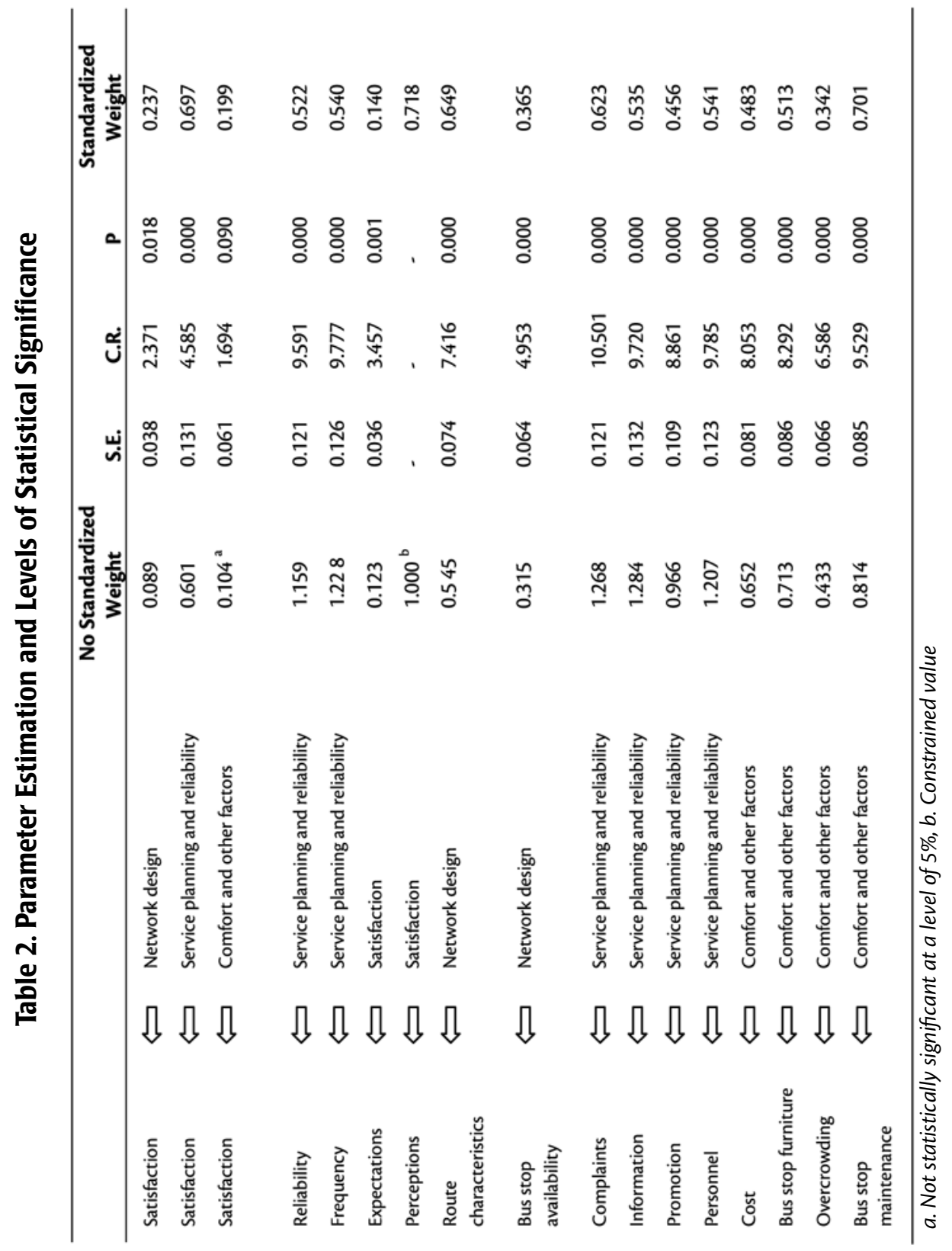




\section{Table 3. Goodness of Fit Indexes}

\begin{tabular}{lr}
\hline Indexes & Values \\
\hline Chi-square & 304.705 \\
Goodness of fit index (GFI) & 0.947 \\
Comparative fit index (CFI) & 0.877 \\
Adjusted goodness of fit index (AGFI) & 0.922 \\
Root mean square residual (RMR) & 0.150 \\
Root mean square error of approximation (RMSEA) & 0.066 \\
\hline
\end{tabular}

The endogenous latent variable, indicating global customer satisfaction, is best explained by the indicator of the quality level perceived by the user (perceptions variable), whose coefficient has a value of 0.718 . On the other hand, the indicator of the quality level expected by the user has a lower value (0.140).

The model offers empirical findings and practical implications. It can be used for investing in some attributes to improve the service by taking into account the strength of the relationship between the variables introduced. In this case, the model suggest that an improvement of the service in terms of service planning and reliability can be more convenient for transport operators because the service planning and reliability latent variable has the greatest effect on global customer satisfaction.

\section{Conclusions}

In this article a structural equation model has been proposed to show the relationship between passenger satisfaction on bus services and the attributes of the services supplied. Although SEM methodology is well known and widely applied in several fields of research, presently there are not many practical applications in public transport, and specifically for measuring customer satisfaction. In this research we have applied this methodology on the basis of needs and expectations expressed by customers of a bus service. The proposed model identifies service quality attributes to improve, with the aim of offering bus services characterized by higher levels of quality.

The major limitation of this research is that the experimental context is circumscribed, because the sample survey was addressed to a specific category of users - students of a university campus. A more accurate analysis of service quality 
in public transport should be based on a survey addressed to all categories of public transport users. However, in this specific case, the students are a relevant part of the population that uses bus transit in the urban area of Cosenza. In spite of its limitation, this study could be a starting point for more exhaustive research.

\section{References}

Andreassen, T.W. 1995. (Dis)satisfaction with public services: The case of public transportation. Journal of Services Marketing 9: 30-41.

Arbuckle, J. L., and W. Wothke. 1995. AMOS 4.0 user's guide. Chicago: SmallWaters Corporation.

Bagozzi, R. P. 1994. Structural equations models in marketing: Basic principles.

In Principles of Marketing Research, R. P. Bagozzi, ed. Cambridge: Blackwell, 317-385.

Bamberg, S., and P. Schmidt. 1998. Changing travel-mode choice as rational choice: Results from a longitudinal intervention study. Rationality and Society 10(2): 223-252.

Boari, G. 2000. Uno sguardo ai modelli per la costruzione di indicatori nazionali di customer satisfaction. In Valutazione della qualità e customer satisfaction: il ruolo della statistica. Milano: Vita e Pensiero, 317-336.

Bollen, K. A. 1989. Structural equations with latent variables. New York: Wiley.

Carroll, J. D. 1953. An analytic procedure for approximating simple structure in factor analysis. Psychometrika 18: 23-27.

Cuomo, M.T. 2000. La customer satisfaction. Vantaggio competitivo e creazione di valore. Padova: CEDAM.

Eskildsen, J. K., and J. J. Dahlgaard. 2000. A causal model for employee satisfaction. Total Quality Management 11(8):1081-1094.

Fabbris, L. 1997. Statistica multivariata. Analisi esplorativa dei dati. Milano: McGraw-Hill Libri Italia.

Fillone, A. M., C. M. Montalbo, and N. C. Tiglao. 2005. Assessing urban travel: A structural equations modeling (SEM) approach. Proceedings of the Eastern Asia Society for Transportation Studies 5:1050-1064. 
Golob, T. F. 2003. Structural equation modeling. In Transportation systems planning, K.G. Goulias, ed. Boca Raton: CRC Press, 11:1-23.

Grace, J. B., and B. H. Pugesek. 1997. A structural equation model of plant species richness and its application to a coastal wetland. The American Naturalist 149(3).

Guttman, L. 1954. Some necessary conditions for common factor analysis. Psychometrika 19: 146-161.

Joreskog, K.G. 1973. Analysis of covariance structures. In Multivariate Analysis-III, P. R. Krishnaiah, ed. New York: Academic Press, 263-285.

Joreskog, K. G., and D. Sorbom. 1988. PRELIS: A program for multivariate data screening and data summarization. A preprocessor for LISREL. Chicago: SSI, Inc.

Joreskog, K. G., and D. Sorbom. 1989. LISREL 7: A guide to the program and applications. Chicago: SPSS, Inc.

Joreskog, K. G., and D. Sorbom. 1995. LISREL 8: Scientific Software International. Chicago: Inc.

Kaiser, H. F. 1960. The application of electronic computers to factor analysis. Educational and Psychological Measurement 20: 141-151.

Karlaftis, M. G., J. Golias, and E. Papadimitriou. 2001. Transit quality as an integrated traffic management strategy: Measuring perceived service. Journal of Public Transportation 4 (1).

MacCallum, R. C., and J. T. Austin. 2000. Applications of structural equation modeling in psychological research. Annual Review of Psychology 51:201-226.

MacLean, S., and K. Gray. 1998. Structural equation modelling in market research. Journal of the Australian Market Research Society.

Manaresi, A., G. Marzocchi, and G. Tassinari. 2000. La soddisfazione del cliente dei servizi di segreteria universitaria: un modello a equazioni strutturali. In Valutazione della qualità e customer satisfaction: il ruolo della statistica. Milano: Vita e Pensiero, 291-316.

Mitchell, R. J. 1992. Testing evolutionary and ecological hypotheses using path analysis and structural equation modelling. Functional Ecology 6:123-129. 
Muthén B., D. Kaplan, and M. Hollis. 2006. On structural equation modeling with data that are not missing completely at random. Psychometrika 52(3): 431-462.

Tam, Mei Ling, Mei Lang Tam, and W. H. K. Lam. 2005. Analysis of airport access mode choice: A case study in Hong Kong. Journal of the Eastern Asia Society for Transportation Studies 6:708-723.

Washington, S. P., M. G. Karlaftis, and F. L. Mannering. 2003. Statistical and econometric methods for transportation data analysis. Florida: Chapman \& Hall/CRC Press.

Wiley, D. E. 1973. The identification problem for structural equation models with unmeasured variables. In Structural Equation Models in the Social Science, A. S. Goldberger and O. D. Ducan, eds. New York: Seminar Press, 69-83.

\section{About the Authors}

LAURA EBol (laura.eboli@unical.it) is Ph.D. student in technologies and environmental planning at the University of Calabria, Italy, where she has undertaken research in transit planning and service quality in public transport. She holds a master's degree in transport systems management from the University of Calabria.

Gabriella MAZzULla (g.mazzulla@unical.it) received a Ph.D. in road infrastructure and transportation systems in 2002 from the University “Federico II," Naples, Italy. She is a researcher in transportation engineering in the Faculty of Engineering at the University of Calabria, Italy. She teaches planning of transport systems and urban and metropolitan transport. Her dominant areas of research are analysis, modelling, and estimation of transportation demand. 